\title{
PENGEMBANGAN PRODUK GENTENG TANAH LIAT DENGAN INTEGRASI QFD DAN VALUE ENGINEERING
}

\author{
DYAH RETNO P \\ Jurusan Teknik Industri Universitas Muhammadiyah Malang \\ Jalan Raya Tlogomas 248 Malang \\ E-mail: retno@umm.ac.id
}

\begin{abstract}
One of the construction material product that's have highly required in constructing a house is house roof that Is roof tile. On of the producen that's produce its in big scale is in Wendit, a country side of Mangliawan. This product as people known is calls as Wendit roof tilet. Wendit produce its roof tile in low quality and cost of its that people prefer choose another roof tile product that have more level either in cost also quality. If this condition is continue without a will to improve its quality, distribution and much more according to satisfy customer desire roof tile producen of Wendit in country side of Mangliawan will close down. A side impact of its degradation is will decreasing the earnings of country side society of Mangliawan and also they social economics in matter the loost of their only life-way to gain a money will decreasing a level of life in social economic and also rise-up the number of unemployment. To answer this problematic this research covered: identification requirement of customer and translating into characteristic of performance by using QFD, developing alternative of design and also Value product for the alternative with Value Engineering. Attribute wanted by customer to tile product for example model, strong, refinement, do not be bars, cool, tile size is not undersize, is easy to attached, price. Satisfaction of customer to the attributes when measured with scale 5 is have good with score above 3. By attention tile industry of Wendit exist in Worse luck, hence technical action and attribute which must be done conducted by tile industry of Wendit is as according to priority shall be as follows: repair of model according to desire of market, adjustment of size measure, printer appliance or of desk have to is made from good materials, have to pay attention pressure at the time of printing, one who do printing process have to which is experienced to be, adapted for by size measure of pres concrete, tile materials have to really solid, process combustion with heat which enough.
\end{abstract}

Key words: fuction, value, designer, customer

\section{PENDAHULUAN}

Ketidakmampuan genteng wendit bersaing dengan industri genteng lainnya menyebabkan genteng wendit terpuruk. Hal ini disebabkan karena kualitasnya kurang bagus sehingga konsumen lebih menyukai produk genteng dari daerah lain salah satunya genteng Tulungagung. Sehingga genteng wendit tersisihkan di kota sendiri dan tidak dapat diterima oleh konsumen sekitar Malang. Dengan kondisi tersebut maka pihak industri genteng dari daerah lain justru memasok genteng ke Malang untuk memenuhi kebutuhan warga Malang. Oleh karena itu, perlu dilakukan usaha-usaha untuk menghasilkan produk genteng wendit yang berkualitas yang pada akhirnya mampu meningkatkan daya saing.

Quality Fuction Deployment (QFD) merupakan metode desain yang sangat efisien dalam mengidentifikasikeinginan dankebutuhankonsumen dan menerjemahkan kebutuhan tersebut kedalam karakteristik performansi (Tjiptono dan Anatasya, 2001). Sedangkan VE merupakan metode desain yang effisien untuk mendapatkan alternatif dengan biaya yang sekecil-kecilnya dengan memenuhi performansi tertentu (Mile, 1972). Berdasarkan keunggulan tersebut, maka integrasi kedua metode akan didapatkan alternatif desain produk yang memiliki Value tinggi. Value sebuah produk merupakan perbandingan performansi dan biaya (Dell Younker, 2003). Dengan mengintegrasikan kedua metode tersebut maka performansi produk menjadi tinggi karena kebutuhan konsumen diidentifikasi dan dipenuhi dengan QFD, sedangkan biaya dapat ditekan seminimal mungkin dengan Value Engineering.

Berdasarkan pemaparan di atas maka permasalahan yang akan diangkat dalam penelitian ini adalah mengembangkan produk 
genteng Wendit yang berkualitas, yang mampu memenuhi selera konsumen dan harganya relatif murah dengan mengintegrasikan konsep Quality Function Deployment dan Value Engineering.

\section{METODE}

Penelitian ini bertujuan untuk mendapatkan beberapa prototype produk genteng dimana proses desain dilakukan dengan mengintegrasikan 2 metode desain, yaitu QFD dan Value Engineering. Penelitian ini dilakukan dengan 2 tahap, yaitu Tahap QFD dan tahap VE.

Tahap QFD melakukan identifikasi kebutuhankebutuhan konsumen dan menerjemahkannya ke dalam karakteristik performansi. Pada tahap ini akan dibuat House of Quality (HOQ) untuk menentukan: Tingkat kepentingan dan kepuasan dari tiap kebutuhan konsumen, Tingkat kepuasan produk pesaing, Seberapa besar kemampuan performansi/respon teknis mampu memenuhi kebutuhan-kebutuhan tersebut (prioritas respons teknis).

Pada tahap Value Engginering menentukan alternatif desain yang diperoleh pada tahap II. Jika Value yang diperoleh lebih tinggi dibandingkan Value produk awal maka dilanjutkan dengan pembuatan gambar desain dan prototype genteng. Namun jika tidak, maka proses penelitian kembali lagi ketahap I dengan mempertimbangkan kembali biaya-biaya yang diperlukan dan tingkat kepentingan kebutuhan konsumen.

Tahapan yang dilakukan dalam proses Value Engineering. (1) Tahap informasi (information phase). Tahap ini bertujuan untuk mengumpulkan sebanyak-banyaknya informasi dan pengetahuan tentang desain suatu produk seperti rancangan desain. Tahap Informasi berasal dari hasil rancangan QFD dengan menghasilkan alternative desain. (2) Tahap kreatif (creative phase). Tahap ini bertujuan untuk mengembangkan sebanyak mungkin alternatif desain yang bisa memenuhi fungsinya. (3) Tahap analisis (judgment phase). Tahap ini untuk menganalisis berbagai ide-ide untuk mengetahui kelebihan dan kekurangan kombinasi berbagai desain alternatif. Tahap ini dilakukan untuk membantu dalam mendapatkan desain alternatif yang paling sesuai. (4) Tahap pengembangan (development phase). Dari fase penilaian didapatkan suatu ide atau alternatif yang terbaik dan alternatif tersebut dikembangkan pada fase pengembangan. Hasil pengembangan disusun menjadi laporan tertulis yang berisi rekomendasi bagi alternatif yang bersangkutan, dan selanjutnya diadakan analisis terhadap biaya-biaya dari alternatif yang terpilih, dilakukan perhitungan nilai, dan untung rugi dari tiap alternative desain. (5) Tahap rekomendasi (recommendation phase). Pada tahap ini hasil dari serangkaian tahapan tersebut dipresentasikan secara lengkap.

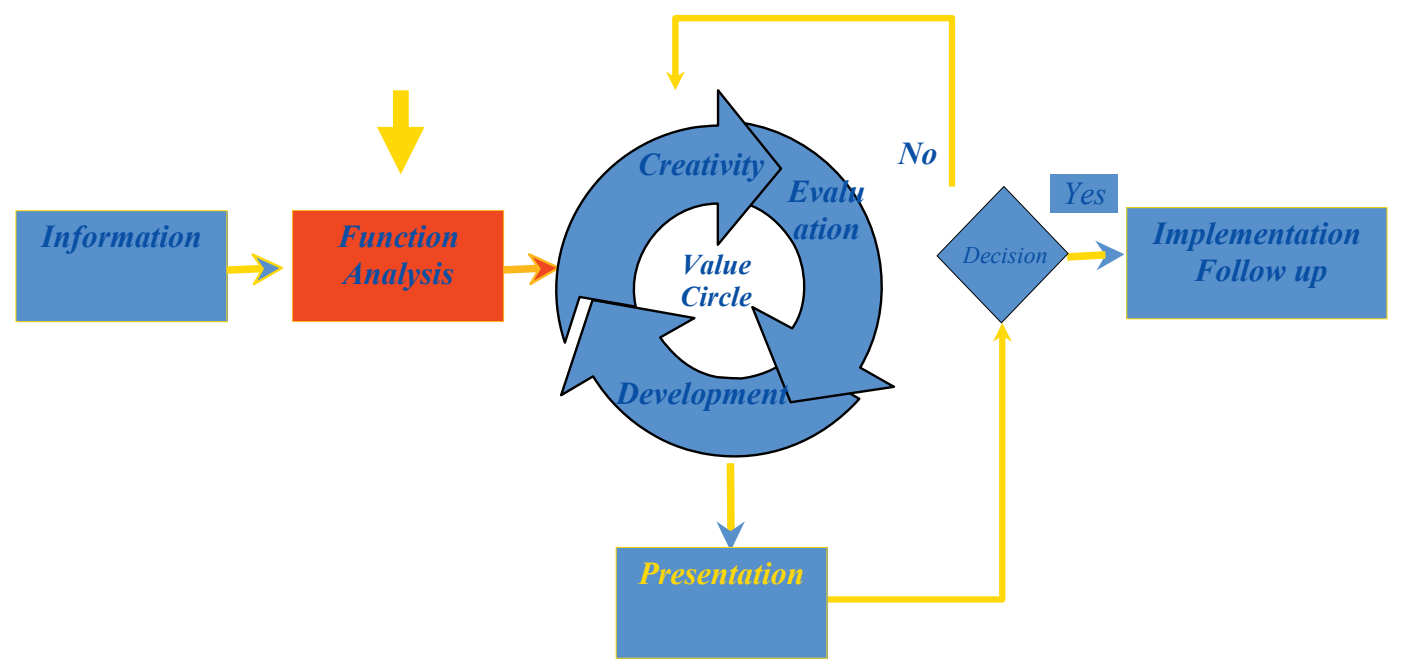

Gambar 1. Tahapan proses desain produk dengan value engineering 


\section{HASIL DAN PEMBAHASAN}

Atribut yang dipentingkan konsumen dalam membeli genteng berdasarkan nilai dari importance to customer sebagai berikut.

Model, konsumen menginginkan model yang tidak monoton sehingga model genteng dapat bervariasi sesuai dengan selera konsumen atau keinginan model genteng yang dikehendaki, atribut ini cukup penting diperhatikan karena nilainya paling tinggi di antara atribut yang lainnya, yaitu sebesar 9.23.

Dingin, atribut dingin ini mempunyai bobot sebesar 9,21 merupakan urutan kedua. genteng yang dingin memiliki pengertian bahwa dengan genteng tersebut menyebabkan liat udara di dalam ruangan terasa sejuk sehingga pengguna merasa nyaman.

Ukuran genteng tidak terlalu kecil, konsumen menginginkan ukuran genteng yang seperti ukuran pres beton tetapi bahan bakunya terbuat dari tanah liat. Ukuran genteng yang terlalu kecil dapat mempengaruhi bentuk genteng dan tidak memperindah atap rumah. Sehingga dalam mendesain usulan genteng yang baru ukuran disesuaikan dengan ukuran genteng pres beton. Atribut ini sangat penting untuk diperhatikan karena bobot yang didapat sebesar 9,16 merupakan urutan ketiga dari sembilan atribut.

Atribut halus merupakan atribut yang menduduki urutan keempat dari sembilan atribut dengan bobot sebesar 8,84, genteng yang halus dapat dipengaruhi oleh proses pembuatan genteng dalam hal ini dalam proses pengayaan pasir, apabila proses pengayaan kurang sempurna maka genteng yang dihasilkan kasar.

Presisi merupakan atribut yang kelima dengan bobot sebesar 8,77, konsumen menginginkan atribut yang presisi karena berhubungan dengan mudahnya pemasangan genteng, semakin genteng mudah dipasang maka akan semakin cepat proses pemasangannya.

Nilai goal ditentukan dengan membandingkan nilai tingkat kepentingan pelanggan, tingkat kepuasan pelanggan dan pesaing. Penentuan goal ini bertujuan untuk meningkatkan performansi kepuasan genteng wendit terhadap konsumen. Penentuan nilai goal yang diberikan oleh pihak genteng wendit adalah antara 3 hingga 5 hal ini dimaksudkan agar konsumen genteng wendit merasa puas dengan produk genteng wendit seperti halnya yang diberikan oleh para pesaing atau bahkan melebihi kepuasan yang diberikan oleh para pesaing.

Atribut genteng yang harus segera dipenuhi (dianggap sangat penting oleh konsumen) pihak genteng wendit adalah model, dingin, ukuran genteng tidak terlalu kecil, halus, presisi.

Improvement ratio menunjukkan ukuran atau nilai yang perlu dilakukan pihak genteng Wendit dalam meningkatkan level performansinya. Nilai ini dihitung dengan membagi nilai goal yang ditetapkan dengan tingkat kepuasan yang diberikan kepada pelanggan. Urutan 4 besar nilai improvement ratio adalah pada atribut-atribut berikut: model, dingin, ukuran genteng tidak terlalu kecil, presisi. Dengan nilai improvement ratio terbesar adalah pada atribut model yang berarti bahwa pihak genteng wendit harus dapat mengubah model genteng yang ada sekarang sesuai dengan selera konsumen sehingga model genteng dapat mengikuti perkembangan zaman. Sedangkan nilai improvement ratio terendah adalah pada atribut harga

Priorities technical responses merupakan tahap mencari urutan prioritas dari respons teknis. Prioritas ini dapat dicari dengan menghitung terlebih dahulu kontribusi relatif setiap respon teknis terhadap atribut, urutan 6 besar nilai kontribusi respons teknis adalah: perbaikan model sesuai keinginan pasar, penyesuaian ukuran, alat pencetak atau desk harus terbuat dari bahan yang bagus, memperhatikan tekanan padasaatmencetak, orang yang mengerjakan proses pencetakan harus yang berpengalaman, disesuaikan dengan ukuran pres beton.

Atribut yang paling diinginkan oleh konsumen mayoritas bisa dikatakan sudah diberikan secara baik oleh pihak industru genteng wendit. Hal ini terlihat dari skor kepuasan yang sudah berada di atas enam untuk atribut, harga , menahan beban, halus, dan tidak mudah retak. Meskipun demikian, perlu dilihat apakah empat pesaing genteng yang memberikan kepuasan yang lebih tinggi. Bila demikian yang terjadi, maka atribut ini juga harus ditingkatkan meskipun konsumen sebenarnya sudah puas. Dengan demikian diharapkan industri 
genteng wendit lebih baik dibanding keempat pesaingnya. Ternyata para pesaing genteng A, B,C,D lebih baik skornya di atas skor genteng wendit dalam atribut, model, ukuran genteng, presisi, harga, dingin, tidak mudah retak, halus.

Berdasar benchmarking ini maka rekomendasi final untuk tingkat kepentingan atribut dapat dilihat pada Tabel 1.

Model genteng didapat dari hasil analisis QFD disitu menunjukkan bahwa konsumen mengiginkan perbaikan pada desain genteng dari tanah liat agar penjualan meningkat, maka pada proses selanjutnya peneliti menekankan pada keinginan konsumen tersebut. Diagram FAST adalah alat untuk menjabarkan lebih lanjut keinginan konsumen berdasarkan fungsinya sehingga pengembangan tidak salah sasaran Kazan, G. (2006). Yang akhirnya didapatkan tiga fungsi pada level pertama, memperindah atap, kenyamanan ruangan dan menahan beban. Fungsi level kedua memiliki arti penjabaran lebih detail dari fungsi level pertama, yaitu bertujuan untuk lebih menspesifikkan keinginan konsumen. Pada fungsi memperindah atap terpilih genteng dengan model dan bahan tanah liat 1, cor 1, cor 2. Fungsi kenyamanan ruangan terpilih genteng tanah liat 1 , tanah liat 2 , tanah liat 3. Sedangkan untuk fungsi menahan beban adalah genteng tanah liat 1 , cor 1 , cor 2 , cor 3 .

Perhitungan bobot fungsi dimaksudkan untuk mengetahui fungsi yang paling utama untuk dikembangkan. Berdasarkan perhitungan bobot fungsi di atas dapat dianalisis bahwa masing masing fungsi memiliki nilai eigen vectornya yang memiliki arti nilai eigen vector tertinggi merupakan fungsi paling utama yang harus dikembangkan.

Performansi genteng menunjukkan bahwa genteng tersebut telah memiliki kriteria dan fungsi-fungsi yang diinginkan konsumen dan produsen dapat memenuhinya, ini sama dengan bobot fungsi, nilai terbesar adalah yang terbaik. Tetapi bukan berarti itu yang diproduksi, masih tergantung pada biaya yang terendah dengan harapan bisa diproduksi besar-besaran dan produsen mendapatkan keuntungan yang besar.

6 alternatif desain sebagai berikut: alternatif 1 genteng tanah liat karang pilang; alternatif 2 genteng tanah liat layur; alternatif 3 genteng tanah liat desain baru; alternatif 4 genteng cor 1 ; alternatif
Tabel 1. Rekomendasi Final untuk Tingkat Kepentingan Atribut

\begin{tabular}{ll}
\hline \multicolumn{1}{c}{ Atribut } & \multicolumn{1}{c}{ Keterangan } \\
\hline Model & Sangat penting sekali \\
Kepresisian & Sangat penting sekali \\
Ukuran tidak terlalu kecil & sangat penting sekali \\
Mudah dipasang & sangat penting \\
Tidak mudah retak & penting \\
Halus & penting \\
\hline
\end{tabular}

5 genteng cor 2 ; alternatif 6 genteng cor 3 seperti pada Gambar 2-7.

Dalam melakukan analisis dan desain peningkatan genteng, perlu melibatkan sebanyak mungkin fungsi dari desain genteng tersebut, sehingga mendapatkan suatu desain genteng yang berkualitas. Pemilihan desain terbaik berdasarkan pada estimasi biaya terendah dari alternatif desain. Nilai ini dinyatakan sebagai perbandingan rasio antarperformansi yang diberikan oleh genteng dan biaya-biaya yang dikeluarkan untuk mengadakan fungsi-fungsi yang diberikan oleh desain genteng.

Besarnya performansi didapatkan berdasarkan hasil pengolahan data oleh masing-masing elemen sistem untuk tiap alternatif desain, sedangkan biaya yang dipergunakan adalah biaya yang dikeluarkan untuk proses produksi. Value adalah sebuah nilai dari produk yang didasarkan pada fungsi dan biaya yang dikeluarkan untuk menghasilkan produk, sehingga produk tersebut memiliki ukuran pangsa pasar tersendiri, artinya pasar bisa memilih jenis produk sesuai yang diinginkan dengan harga yang terjangkau. Jika dilihat pada enam hasil value yang berbeda, masing masing memiliki arti tersendiri. Jika nilai value tinggi maka dapat diartikan bahwa harga genteng tersebut murah karena dengan rumus yang sama dan performansi serta angka konversi rupiah yang sama, sehingga desain yang akan dipilih untuk diproduksi adalah genteng yang memiliki nilai value yang tinggi.

Alternatif 3 Genteng tanah liat (desain baru sesuai keinginan konsumen) memiliki Value 25,49 yang berarti bahwa genteng tersebut telah memenuhi fungsi-fungsi pada level 1, yaitu memperindah atap, menciptakan kenyamanan ruangan, serta kemampuan menahan beban dan terpenuhi pula fungsi pada level ke dua, yaitu permukaan pasang yang rata, presisi, padat, 

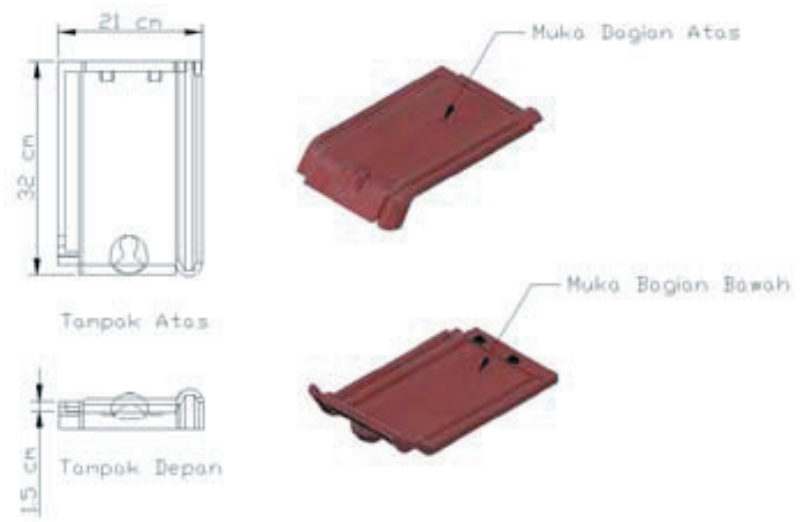

Gambar 2. Alternatif 1 genteng tanah liat karang pilang
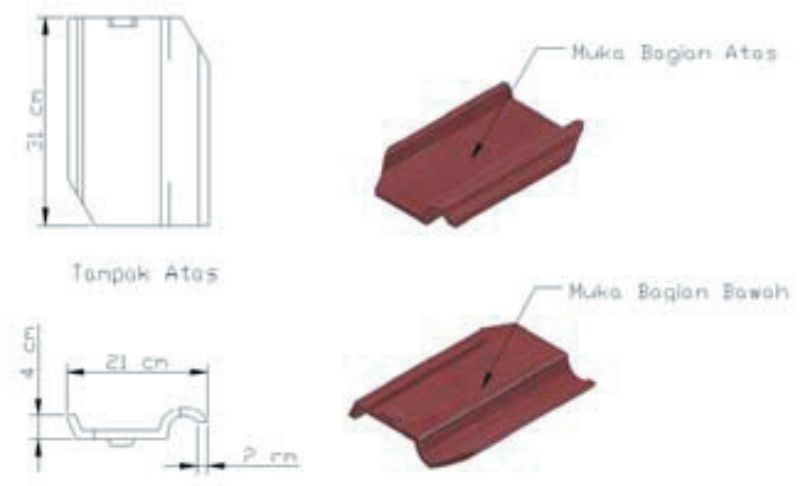

Tompak Depan

Gambar 3. Alternatif 2 genteng tanah liat layur

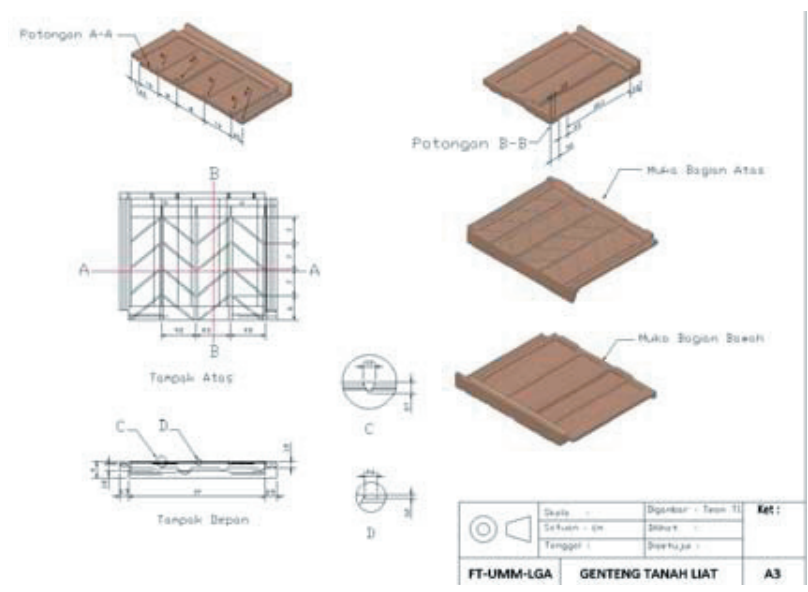

Gambar 4. Alternatif 3 genteng tanah liat desain baru
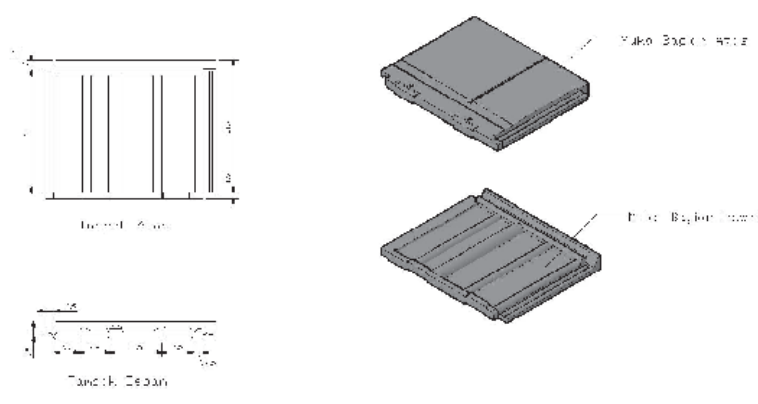

Gambar 5. Alternatif 4 genteng cor 1
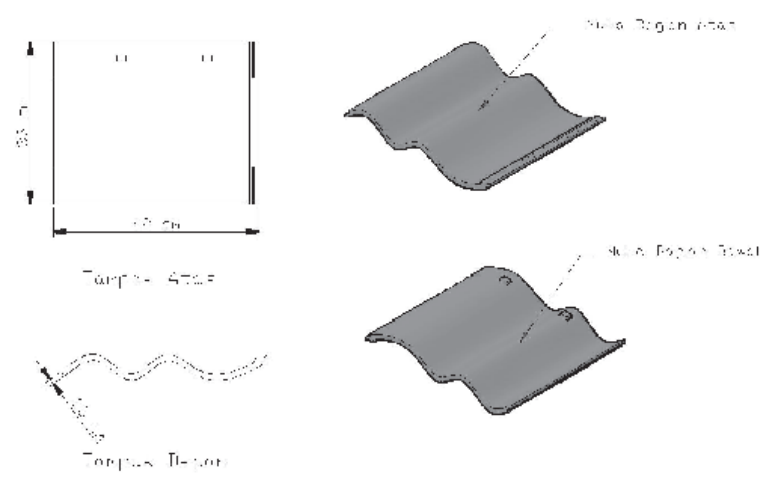

Gambar 6. Alternatif 5 genteng cor 2
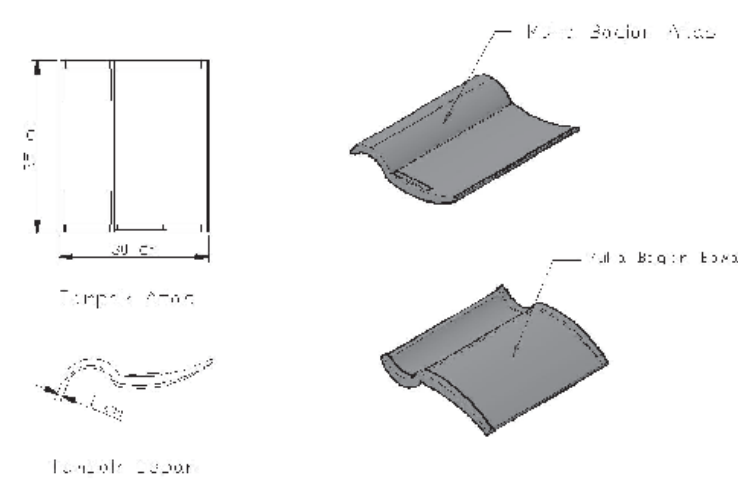

Gambar 7. Alternatif 6 genteng cor 3 
kondisi ruangan yang dingin, tidak bocor, tidak menimbulkan suara, tidak keropos, tidak mudah retak, ketebalan cukup, berat cukup.

\section{SIMPULAN}

Atribut yang paling diinginkan oleh konsumen terhadap produk genteng meliputi model, dingin, ukuran genteg tidak terlalu kecil, halus dan presisi. Di antara atribut yang diinginkan oleh konsumen pengguna genteng dengan nilai kepentingannya lebih besar adalah model. Berdasarkan hasil pemilihan desain dengan menggunakan value engineering berdasarkan nilai dari sebuah desain yang paling besar adalah desain 3 dengan nilai 25,49 .

\section{DAFTAR PUSTAKA}

Besterfield, D.H., dkk, 1999. Total Quality Management, Prentice Hall.

Cohen, L., 1995. Quality Function Deployment: How to Make QFD Work for You. Massachuset: Addision Wesley Publishing Company.
Dell.Younker, 2003, Value Engineering Analysis and Methodology, Marcel Dekker, Inc.

Gargione, Luiz Antônio, 1999. Using Quality Function Deployment (QFD) in the Design Phase of an Apartment Construction Project, Proceeding IGLC-7, 26-28 July 1999, University of California, Berkeley, CA, USA.

Kazan, G., 2006. Inovasi dan Seni pada Value Engineering untuk Pengolahan Konstruksi, Jurnal Sosioteknologi.

Mile, L.D., 1972. Technique of Value Analysis and Engineering. New York: McGraw-Hill Book Company.

Park, R., 1999. Value Engineering a Plan for Invention, St. Lucie Press, Boca Raton London New York Washington, D.C

Radcliffe, 2004. Integrating Sustainability Aspects into the Earky Stages of the Value Engineering Methodologhy. Thesis.

Tjiptono, F., dan Anastasia, D., 2001. Total Quality Manajement. Yogyakarta: Andi Offset.

Zimmerman, Z.W., Hart, G.D., 1988. Value Engineering A practical Approach for Owners, Designers Contractors, CBS. 